\title{
Atuação do psicólogo escolar na perspectiva de proposições legislativas
}

\author{
Mariana Guimarães Pasqualini \\ Marilene Proença Rebello de Souza \\ Cárita Portilho de Lima
}

\begin{abstract}
Resumo
Esta pesquisa insere-se na discussão relativa à inserção de psicólogos na Educação Básica, visando contribuir para a construção de políticas públicas em uma perspectiva histórico-crítica. Considerou-se fundamental analisar proposições legislativas que versam sobre a inserção do psicólogo neste campo, buscando desvelar como a Psicologia se faz presente e quais demandas sociais reivindicam a presença desses profissionais na Educação. Realizou-se pesquisa documental nos sites do Congresso Nacional, Assembleia Legislativa do Estado de São Paulo e Câmara Municipal de São Paulo que resultou na análise de 31 proposituras legislativas. Nota-se que a expectativa que se tem sobre a atuação de psicólogos na Educação permanece predominantemente focada no indivíduo, com viés clínico e vinculada a uma concepção instrumental de Educação. Constata-se, portanto, a necessidade de ampliarmos ações junto às representações legislativas e à sociedade, em geral, que possibilitem a elaboração de proposições condizentes com o compromisso ético-político firmado pela área da Psicologia Escolar e Educacional na Educação Básica.
\end{abstract}

Palavras-chave: Políticas Públicas, orientação vocacional, escolas.

\section{School psychologist's performance from the perspective of legislative proposals}

\begin{abstract}
This work is part of the discussion on inclusion of psychologists in Basic Education. We aim at contributing to the construction of public policies from with the historical-critical perspective. We consider essential to analyze legislative proposals that deal with the insertion of psychologists in this field. We propose to investigate how Psychology is present in the school and what are the social demands that claim psychologist's presence in education. We conducted a documental research in the following legislative houses - the National Congress, the Legislative Assembly of São Paulo and in the archives of São Paulo City Hall -which resulted in the analysis of 31 legislative propositions. The results reveal that psychologists are expected to work predominantly on the individual, with a clinical tendency and linked to an instrumental concept of education. We argue that it is necessary to enlarge the articulation with the legislative representatives and with society as a whole so that we can develop propositions which help construct ethical-political commitment, expected from School Psychology in Basic Education.
\end{abstract}

Keywords: Public policies, vocational guidance, schools.

\section{Actuación del psicólogo escolar bajo perspectiva de propuestas legislativas}

\section{Resumen}

Esta investigación forma parte de la discusión relativa a la inclusión de psicólogos en la Educación Básica y tiene el objetivo de contribuir para la construcción de políticas públicas en perspectiva histórico-crítica. Se consideró fundamental analizar propuestas legislativas que tratan sobre la inclusión del psicólogo en este campo con la intención de desvelar cómo la Psicología se presenta y cuáles son las demandas sociales que reivindican la presencia de estos profesionales en la Educación. Se realizó investigación documental en los sitios web del Congreso Nacional, Asamblea Legislativa del Estado de São Paulo y Cámara Municipal de São Paulo que resultó en el análisis de 31 propuestas legislativas. Es notoria que la expectativa que se tiene sobre la actuación de psicólogos en la Educación permanece predominantemente centrada en el individuo con sesgo clínico y vinculada a una concepción instrumental de Educación. Se constata por lo tanto la necesidad de ampliarse acciones junto a las representaciones legislativas y a la sociedad en general que permitan la elaboración de propuestas coherentes con el compromiso éticopolítico firmado por el área de Psicología Escolar y Educacional en la Educación Básica.

Palabras clave: Politicas publicas, orientación vocacional, escuelas. 


\section{Introdução}

O presente estudo insere-se na interface entre a Psicologia Escolar e Educacional e as políticas públicas educacionais. A Psicologia Escolar e Educacional tem desenvolvido, pelo menos nos últimos trinta anos, relevante discussão no que tange à formação/atuação do psicólogo no campo da educação. Nesse contexto surgiram questionamentos a respeito das bases epistemológicas que sustentam a intervenção do psicólogo escolar, bem como sobre qual seria o seu papel social, evidenciando que era necessário buscar perspectivas que superassem modelos subjetivistas e objetivistas de conceber o fenômeno educacional (Patto, 1990; Tanamachi, 2002). O desenrolar dessas críticas resultou no deslocamento do eixo de análise do fenômeno educacional do indivíduo para os determinantes históricos, sociais e políticos que atravessam e constituem a vida diária escolar.

A retomada do compromisso político da atuação do psicólogo na construção de uma escola pública democrática e de qualidade implica em conhecermos quais concepções e propósitos estão orientando a elaboração das políticas públicas educacionais. O discurso oficial expressa concepções a respeito da educação e da sociedade que norteiam a elaboração de propostas de ações no campo educacional, as quais se concretizam em práticas que determinam o cotidiano escolar (Souza, 2010). Desse modo, faz-se necessário conhecermos quais os compromissos políticos e pedagógicos trazidos pelas políticas públicas para que se compreenda o fenômeno educacional em toda a sua complexidade. A partir dessa perspectiva, é de fundamental importância conhecer e analisar quais políticas estão sendo propostas no campo da educação e desvelar como os conhecimentos produzidos pela academia em direção a uma Psicologia Escolar crítica estão sendo apropriados pelas pessoas, grupos e/ou entidades que participam da elaboração das propostas políticas que versam sobre a inserção do psicólogo no campo da educação. Isto é, compreender quais demandas sociais sustentam e reivindicam a presença de profissionais psicólogos na área da educação.

Diante disso, um dos espaços privilegiados para que sejam conhecidas as tendências e as propostas que estão sendo gestadas no âmbito da sociedade são as casas legislativas, onde os interesses são representados e as forças políticas em jogo expressam as tensões existentes entre os diversos segmentos sociais. Trabalhos recentes (Oliveira, 2009; Souza \& Cunha, 2010) têm demonstrado a necessidade de darmos mais atenção a essa instância social, destacando a importância dos embates e dos textos legislativos que, quando aprovados, instauram mudanças substanciais nas diversas esferas do cotidiano e conduzem a ações no plano do Executivo, gerando políticas públicas. Certamente as políticas públicas não se restringem à construção de proposições legislativas, mas essas são uma forma de materialização das primeiras.

Desse modo, foram buscadas respostas a questões fundamentais como: a) que concepção de Psicologia no campo da Educação se faz presente nas propostas elabo- radas pelo Poder Legislativo?; b) O que se espera do psicólogo no campo educacional?; c) Há espaço para a construção de práticas comprometidas com a transformação da realidade social? Compreender a concepção de Psicologia Escolar e Educacional que constitui os projetos de leis pode ser um norteador para os profissionais da área que lutam pela construção de ações políticas mais condizentes com o compromisso ético-político firmado com a educação pública.

\section{Método}

Inicialmente, realizou-se um mapeamento dos Projetos de Lei em âmbito federal que dispõem sobre a inserção do psicólogo na Educação Básica. Todavia, o contato com o processo de elaboração das leis nas duas Casas legislativas que compõem o Congresso Nacional - Senado Federal e Câmara dos Deputados - evidenciou que o processo legislativo abarca a tramitação de diversas espécies normativas. Diante da diversidade de proposições sujeitas à deliberação de ambas as Casas, considerou-se que a presente pesquisa deveria centrar-se no conhecimento das Proposições Legislativas (PL) sobre a inserção do psicólogo na Educação Básica. Tendo em vista que tal denominação abarca os Projetos de Lei, a utilização do termo Proposições Legislativas possibilita um maior alcance da pesquisa e condiz de forma mais precisa com a realidade do sistema legislativo brasileiro. Ademais, cabe ressaltar que as Proposições Legislativas constituem-se da seguinte forma: primeiro é exposto um texto em que consta o que parlamentar está propondo a respeito de determinado assunto. Em seguida, é apresentada a Justificativa, isto é, o texto que elenca os argumentos que motivam e sustentam o porquê da elaboração de tal proposição e os motivos pelos quais se acredita que esta deva ser aprovada.

O levantamento das Proposições Legislativas federais que tramitaram e ainda estão tramitando foi feito tendo como instrumento o acesso aos endereços eletrônicos http://www.senado.gov.br e http://www.camara.gov.br. Para o levantamento das proposições legislativas do Estado de São Paulo e do município de São Paulo, utilizaram-se como ferramenta de busca os seguintes endereços eletrônicos: http://www.al.sp.gov.br e http://www.camara.sp.gov.br. Nos endereços eletrônicos pesquisados, somente podem ser visualizados na íntegra (texto e justificação/ justificativa) as Proposições Legislativas (PL) apresentadas a partir do ano de 2001. Assim sendo, optou-se por fazer a análise mais aprofundada das PL elaboradas após tal data. No caso das proposições municipais, não foi possível ter acesso aos textos de justificativa ${ }^{1}$, porém a leitura dos textos dos projetos de lei nos permitiu a apreensão de alguns aspectos que serão analisados em conjunto com as demais proposições.

$1 \mathrm{Na}$ época em que a pesquisa foi desenvolvida não era possível acessar os textos de justificativa das proposições legislativas municipais, entretanto, atualmente é possível acessar as proposições na íntegra no site: http://www.camara.sp.gov.br/ 
O contato com a elaboração das proposições legislativas evidenciou que os textos parlamentares passam por diversas modificações ao longo do processo de tramitação no interior das casas legislativas, sendo a versão final promulgada em norma legislativa ou não conforme a decisão dos parlamentares. Dessa forma, a quantidade de textos encontrados implicou na necessidade de ser adotado um recorte para que fosse possível a realização de uma análise mais aprofundada. Optou-se por analisar a primeira versão das proposições legislativas, isto é, o texto inicial que introduz a temática da inserção do psicólogo no campo da educação.

A análise do corpus dos dados baseou-se no método de análise de prosa, como definida por André (1983). A autora propõe uma abordagem alternativa para a análise de dados qualitativos, que se afasta da conotação técnica comumente associada ao método de análise de conteúdo, permitindo um modo de aproximação mais adequado, que possibilita o trabalho com informações coletadas de diversas formas, entre elas, a análise de documentos. Sugere ainda que os tópicos e temas sejam gerados a partir do contato com os dados e de sua contextualização no estudo que está sendo feito, sendo de suma importância reconhecer o papel da intuição e da subjetividade do pesquisador na escolha das temáticas e assuntos desenvolvidos, assim como do referencial teórico do qual ele parte.

Ao longo da análise das proposições legislativas foram destacados temas e aspectos recorrentes nos textos parlamentares. Entretanto, não houve a preocupação em quantificar a ocorrência desses tendo em vista que a frequência de um item não determina necessariamente seu grau de relevância e uma única aparição de algum aspecto pode revelar dimensões importantes do fenômeno que está sendo estudado (André, 1983).

A leitura das proposições levou à construção de questões que foram utilizadas para nortear a análise, são elas: o que é dito a respeito do quadro educacional brasileiro? Qual concepção de Psicologia na Educação se faz presente? E qual proposta de atuação é defendida? Além disso, a partir dessas leituras reconheceu-se a possibilidade de se dividir em eixos o conjunto de proposições de acordo com a atuação proposta para o psicólogo. Dessa maneira, foram criados os seguintes eixos: Atuação na Educação Básica, Atuação junto a crianças/adolescentes com supostos Transtornos de Aprendizagem, Orientação Profissional e Ensino de Psicologia.

\section{Resultados e discussão}

O mapeamento das Proposições Legislativas ${ }^{2}$ resul- $^{-}$ tou no encontro de 73 proposições, sendo possível o acesso

2 Com intuito de facilitar a exposição, usaremos as seguintes siglas: PLC - proposição legislativa oriunda da Câmara dos Deputados; PLS - proposição legislativa oriunda do Senado; PLALESP proposição legislativa oriunda da Assembleia Legislativa do Estado de São Paulo; PLM - proposição legislativa oriunda da Câmara Municipal de São Paulo. ao texto na íntegra de 31 delas. O presente texto apresentará a análise das Proposições Legislativas pertencentes ao eixo Atuação na Educação Básica, as quais versam sobre a inserção do psicólogo como profissional do campo da Educação e abordam, portanto, de forma mais direta, questões ligadas à atuação do psicólogo escolar. Pertencem a esse eixo: nove proposições oriundas da Câmara Federal, uma do Senado Federal, cinco da ALESP e cinco da Câmara Municipal de São Paulo, totalizando 20 proposições (na próxima página consta o anexo com a relação das proposições analisadas). Dessa forma, tais proposições parlamentares foram encontradas em todas as casas legislativas pesquisadas.

A partir da década de 1940 até os dias de hoje, diversas proposições parlamentares foram localizadas na Câmara dos Deputados e, a partir dos anos 1980, na Assembleia Legislativa do Estado de São Paulo, evidenciando que a inserção do psicólogo na educação esteve e ainda está presente na pauta do sistema legislativo. Apesar da inegável importância de se contextualizar na história educacional brasileira o surgimento de cada uma dessas propostas, por questões metodológicas, nossa análise deter-se-á nas proposições legislativas federais e estaduais elaboradas após o ano de 2001.

A primeira proposição encontrada a respeito de tal temática - PLC 312/1949 - traz o seguinte texto: "Autoriza o tribunal de contas a registrar o termo aditivo entre o Ministério da Educação e Saúde e Helena Antipoff, para desempenho das funções de técnico especializado em proteção social e psicologia educacional". Não foi possível ter acesso ao texto desse projeto de lei na íntegra, mas cabe ressaltar a referência a Helena Antipoff, importante pesquisadora que contribuiu significativamente com a educação brasileira ao fazer críticas, já na década de 1930, ao uso e à interpretação de testes psicológicos que desconsideravam os determinantes sociais, econômicos e culturais do processo de escolarização (Antunes, 2003). Além disso, interessa-nos destacar nessa proposição legislativa o emprego do termo "psicologia educacional".

Com relação à forma como foi nomeado o campo de atuação e pesquisa que se construiu na interface entre a Psicologia e a Educação, no cenário brasileiro, há o trabalho de Souza (2009), que retoma o fato de que a Psicologia Escolar e a Psicologia Educacional permaneceram historicamente como campos distintos, sendo a primeira tida como campo de prática profissional e a última como área de pesquisa em Psicologia. Recentemente tal dicotomia passou a ser questionada no sentido de ser, a partir de uma perspectiva crítica, impossível dissociar teoria e prática na constituição de uma área de conhecimento e atuação comprometida com a transformação da realidade social. Sendo assim, optamos por utilizar o termo Psicologia Escolar e Educacional para nos referirmos a esse campo.

Segundo Meira e Antunes (2003), a Psicologia da Educação configurou-se, no decorrer do século XX, como uma área de conhecimento voltada para questões da Educação e, em especial, da educação escolar. As autoras 
Anexo: Segue abaixo a relação das proposições legislativas (elaboradas após o ano de 2001) listadas de acordo com a Casa Legislativa em que foram apresentadas:

\begin{tabular}{|c|c|}
\hline \multicolumn{2}{|r|}{ CÂMARA DOS DEPUTADOS } \\
\hline PLC 837 - 2003 & $\begin{array}{l}\text { Dispõe sobre a participação de assistentes sociais e psicólogos na estrutura funcional das } \\
\text { escolas. }\end{array}$ \\
\hline PLC 1497 - 2003 & $\begin{array}{l}\text { Dispõe sobre a oferta de Serviços de Psicologia para acompanhamento dos alunos na escola } \\
\text { e na comunidade. }\end{array}$ \\
\hline PLC 1674 - 2003 & $\begin{array}{l}\text { Altera o art. } 25 \text { e acrescenta } \S \text { único à Lei nº 9.394, de } 1996 \text { (LDB), para possibilitar psicólogos } \\
\text { e assistentes sociais escolares no âmbito educacional. }\end{array}$ \\
\hline PLC 2513 - 2003 & $\begin{array}{l}\text { Dispõe que em toda escola, pública e privada, seja obrigatória a presença de profissional da } \\
\text { área de Psicologia. }\end{array}$ \\
\hline PLC 3154 - 2004 & $\begin{array}{l}\text { Dispõe sobre a obrigatoriedade das escolas públicas e privadas contratarem Assistentes Sociais } \\
\text { e Psicólogos. }\end{array}$ \\
\hline PLC 3613 - 2004 & $\begin{array}{l}\text { Dispõe sobre a obrigatoriedade da participação de Psicólogos nos quadros funcionais das } \\
\text { escolas brasileiras. }\end{array}$ \\
\hline PLC 1719 - 2006 & $\begin{array}{l}\text { Cria o Programa de Atendimento Psicopedagógico e Social para atender as escolas da rede } \\
\text { pública e privada de ensino fundamental de todo o território nacional, e dá outras providências. }\end{array}$ \\
\hline PLC 7500 - 2006 & $\begin{array}{l}\text { Acrescenta o art. 86-A à Lei n 9.394, de } 20 \text { de dezembro de 1996, que estabelece as diretrizes } \\
\text { e bases da educação nacional, para determinar a obrigatoriedade da assistência psicológica a } \\
\text { educadores e educandos da educação básica. }\end{array}$ \\
\hline PEC $13-2006$ & $\begin{array}{l}\text { Acrescenta o inciso VIII ao art. } 208 \text { da Constituição Federal de 1988. Explicação da Ementa: } \\
\text { Garante aos alunos de ensino fundamental e médio atendimento por equipe de avaliação } \\
\text { formada por Psicólogos e Assistentes Sociais. Altera a Constituição Federal de } 1988 \text {. }\end{array}$ \\
\hline \multicolumn{2}{|c|}{ ASSEMBLEIA LEGISLATIVA DO ESTADO DE SÃO PAULO } \\
\hline PLALESP 1040 - 2003 & Institui o Serviço Psicológico Escolar nas escolas estaduais de $1 .^{\circ}$ e $2 .^{\circ}$ graus. \\
\hline PLALESP 642 - 2004 & $\begin{array}{l}\text { Obriga a implantação de assistência psicológica e psicopedagógica nos estabelecimentos } \\
\text { educacionais da rede pública estadual }\end{array}$ \\
\hline PLALESP 700 - 2005 & $\begin{array}{l}\text { Uma grande porcentagem de menores vivem em conflito com a sociedade e seu meio familiar, } \\
\text { trazendo dificuldades no aprendizado. Dentro desta ideia, solicitamos a adequação das escolas } \\
\text { com profissionais na área psicológica. }\end{array}$ \\
\hline PLALESP 441 - 2007 & $\begin{array}{l}\text { Assegura atendimento por psicólogos e assistentes sociais aos alunos das escolas públicas de } \\
\text { educação básica. }\end{array}$ \\
\hline PLALESP 442 - 2007 & $\begin{array}{l}\text { Autoriza o Poder Executivo a implantar nos quadros funcionais das escolas estaduais um } \\
\text { profissional na área de psicologia e um na área de assistência social. }\end{array}$ \\
\hline INDICAÇÃO 2410 - 2008 & $\begin{array}{l}\text { Indica ao Senhor Governador providências voltadas à inclusão nas escolas públicas do Estado } \\
\text { de um programa de atendimento por psicopedagogos, a alunos com problemas no aprendizado, } \\
\text { acolhendo a iniciativa da jovem Dality Zanchetta, da Escola Estadual João XXIII, de Americana, } \\
\text { participante do Parlamento Jovem de } 2008 \text {. }\end{array}$ \\
\hline \multicolumn{2}{|r|}{ CÂMARA MUNICIPAL DE SÃO PAULO } \\
\hline PLM 417 - 2007 & $\begin{array}{l}\text { Fixa em todas as unidades de ensino do município de São Paulo a lotação de psicólogo e dá } \\
\text { outras providências. }\end{array}$ \\
\hline PLM $462-2008$ & $\begin{array}{l}\text { Dispõe sobre o atendimento por psicólogos e assistentes sociais a alunos das escolas de ensino } \\
\text { fundamental e médio do município de São Paulo. }\end{array}$ \\
\hline PLM 280 - 2009 & $\begin{array}{l}\text { Dispõe sobre a instituição de programa de assistência social e psicológica nas instituições da } \\
\text { rede municipal de ensino nos níveis infantil, fundamental e médio do município de São Paulo. }\end{array}$ \\
\hline PLM 656 - 2009 & $\begin{array}{l}\text { Dispõe sobre a prestação de serviços de psicologia e de assistência social nas escolas públicas } \\
\text { municipais de São Paulo. }\end{array}$ \\
\hline PLM $669-2009$ & $\begin{array}{l}\text { Institui o programa de assistência médica e psicológica aos professores da rede pública do } \\
\text { município de São Paulo portadores da síndrome de burnout. }\end{array}$ \\
\hline
\end{tabular}


afirmam que a inserção de ideias psicológicas no processo educacional influenciou concepções e práticas pedagógicas, demarcando um lugar de importância para a Psicologia no campo educacional. Nesse contexto, a Psicologia da Educação adquiriu uma autonomia que possibilitou a constituição de uma área de atuação específica da qual emerge, entre outros modos de atuação, a figura do Psicólogo Escolar. Contudo, análises do que vem sendo produzido na área evidenciam que é preciso caminhar no sentido da apropriação efetiva de referenciais teórico-metodológicos que sustentem e consolidem práticas que considerem as múltiplas determinações da realidade educacional e que, a partir disso, a Psicologia possa de fato colaborar com a melhoria da qualidade de ensino oferecido à maioria da população brasileira, culminando em transformações concretas na Educação.

A respeito disso, Souza (2010) afirma que a retomada do lugar político da prática psicológica implica no compromisso primordial com a busca por caminhos para a consolidação de uma escola democrática e de qualidade, exige a ruptura epistemológica com concepções adaptacionistas e demanda da área a construção de uma práxis psicológica frente à queixa escolar. É nesse sentido, afirma a autora, que, ao assumirmos o compromisso político com uma escola democrática, faz-se necessário conhecer os meandros e os princípios que estão orientando a construção de políticas públicas em educação.

Partindo dessa perspectiva, as proposições legislativas analisadas caracterizam-se por abordar a inserção do psicólogo na Educação como profissional que atuará em diversas questões advindas do cotidiano escolar. Os textos parlamentares sugerem a inserção do psicólogo nos quadros funcionais das escolas, como profissional da educação, ou advogam pela criação de serviços/programas de Psicologia Escolar, como pode ser ilustrado pelos trechos da PLALESP 1040/2003 - "Institui o Serviço Psicológico Escolar nas Escolas Estaduais de $1^{\circ}$ e $2^{\circ}$ graus" - e da PLC 7500/2006 - "Acrescenta o art. 86-A à Lei $n^{\circ}$ 9.394, de 20 de dezembro de 1996, que estabelece as diretrizes e bases da educação nacional, para determinar a obrigatoriedade da assistência psicológica a educadores e educandos da educação básica". Desse modo, pode-se dizer que tais propostas legitimam um lugar no contexto escolar para que o psicólogo atue realizando ações e práticas concebidas a partir de referenciais teórico-metodológicos adotados e desenvolvidas por esse campo do conhecimento.

Tendo como pressuposto que a escola é uma instituição social que só pode ser compreendida no interior das relações sociais de produção e, portanto, da estrutura da sociedade que a inclui (Patto, 1990) e considerando como tarefa da Psicologia Escolar e Educacional debruçar-se sobre as inúmeras determinações que produzem e sustentam a queixa escolar (Tanamachi \& Meira, 2003), faz-se necessário expor quais considerações são feitas a respeito da situação do sistema educacional público brasileiro. Nesse sentido, é importante identificar quais são os aspectos da realidade escolar e social elencados como justificativas para as ações propostas para o campo da Educação e, mais es- pecificamente, para a inserção do psicólogo nesse contexto. Em suma, é fundamental reconhecer a partir de qual concepção de escola o psicólogo está sendo convocado a atuar.

Nota-se que as referências feitas ao contexto escolar, quando estas se fazem presentes, focam a questão da evasão, repetência e indisciplina escolar. Esta última apresenta-se predominantemente associada ao fenômeno da violência, como pode ser observado na PLC 2513/2003:

Hoje as taxas de reprovação, indisciplina escolar e abandono dos alunos são alarmantes, acarretando baixa produtividade do sistema educacional brasileiro. É inquestionável que existe uma relação direta entre o desempenho escolar insuficiente e o desajuste social. A violência urbana se reproduz na indisciplina dentro da escola.

Desse modo, a situação das escolas públicas brasileiras é trazida de forma dramática e marcada por elementos como grandes taxas de evasão e a presença de relações entre os diversos participantes do contexto escolar marcadas pela violência. A escola é, então, entendida como algo que sofre passivamente os reflexos da violência, sendo a indisciplina algo que tem suas origens fora do contexto escolar. A realidade escolar que produz cotidianamente frustração em seus participantes, que falha em sua tarefa de ensinar e oferece aos docentes e funcionários salários baixos, formação de má qualidade e os exclui de importantes decisões a respeito do processo pedagógico não é levada em consideração. Do mesmo modo, a indisciplina não é concebida como uma espécie de recurso de sobrevivência adotado pelos alunos enraivecidos diante da qualidade do ensino que recebem e da descrença na possibilidade de alcançar melhores condições de vida pela via da escolarização (Patto, 2010). A explicação para tais comportamentos indisciplinados baseia-se na concepção ideológica de que os alunos e suas famílias são inadequados.

Sendo assim, as explicações trazidas para embasar o que é dito a respeito das escolas da rede pública permanecem focadas em fatores externos ao contexto escolar, ao sistema de ensino e à política educacional. As explicações pautam-se na presença de problemas de origem psicológica e/ou familiar nos alunos que geram dificuldades no processo de escolarização, como pode ser observado na passagem a seguir da PLALESP 1040/2003:

Com efeito, a necessidade de serem equacionadas e atendidas as carências apresentadas por grande número de alunos da rede pública de educação, face aos inúmeros problemas de natureza sócio-econômico psicológico familiar, dependência química, que interferem em seu pleno desenvolvimento pessoal e social, levando-as à indisciplina, à repetência e à evasão escolar, com a conseqüente resposta em termos de marginalização (...).

Nota-se, portanto, a presença da ideia de que a escola precisa repensar suas estratégias pedagógicas e articular serviços, como o de Psicologia, para suprir as deficiências 
individuais dos alunos e/ou as carências oriundas do ambiente familiar, tendo como um dos objetivos principais evitar o aumento da criminalidade. A esse respeito, Patto (2007) afirma que, na história do pensamento educacional brasileiro, a função da escola sempre esteve relacionada mais ou menos intensamente, conforme o período, com a prevenção da criminalidade. A autora afirma que concepções ideológicas sobre a menor capacidade dos alunos pobres para aprender e a ideia de que esses são mais propensos a manifestar comportamentos violentos, seja por questões individuais ou por problemas no ambiente familiar, sempre pautaram a elaboração das reformas e dos projetos educacionais e que a permanência, até os dias de hoje, de concepções preconceituosas a respeito da clientela da escola pública resulta na busca por caminhos e soluções sabidamente equivocados.

Nesse sentido, a ideia de que é preciso propor ações na Educação com vistas a reduzir os gastos com segurança pública ou "corrigir" indivíduos potencialmente delinquentes apresenta-se claramente em propostas parlamentares como a PLC 837/2003 e a PLALESP 441/2007 que compartilham o seguinte trecho:

Os benefícios da superação destas dificuldades de socialização são de várias ordens: primeiro, deve-se destacar o benefício para cada um dos estudantes atendidos que, além de melhorarem sua convivência familiar e escolar, poderão evitar a evasão e alcançar efetivo sucesso escolar e inserção social; (...) por fim, toda a sociedade será beneficiada pela inserção de um cidadão educado e produtivo, reduzindo a possibilidade de receber um indivíduo pouco escolarizado e com altas chances de se transformar em desajustado.

Tal concepção coloca a Psicologia a serviço de uma escola cujo propósito não é a formação intelectual de seus alunos, e sim evitar que esses se tornem "desajustados". É preciso evitar o aumento da criminalidade e acredita-se que a Educação é o caminho para tal. A partir desse ponto de vista, a Educação é tida como autônoma em relação à sociedade, e as determinações sociais do fenômeno educacional são ignoradas (Saviani, 2001). Permanece a concepção ideológica de que uma boa educação para todos seria suficiente para sanar os problemas sociais que, na realidade, são inerentes e constitutivos do modo de produção capitalista.

Há também referências diretas a uma suposta influência negativa de certos arranjos familiares na aprendizagem dos alunos, o que exime as práticas escolares cotidianas e a política de ensino da responsabilidade pelo fracasso escolar da rede pública, como pode ser ilustrado pelo trecho a seguir da PLALESP 1040/2003:

Considerando que a sociedade brasileira, passa por grande crise social, e a desestruturação familiar é uma realidade, que cresce a cada dia, implicando assim em problemas sérios e desvios de personalidades nas crianças e jovens de nossas escolas, necessitando de forma imprescindível profissionais especializados para orientar e encaminhar os alunos da rede de ensino.

Constata-se aparentemente a existência de um padrão abstrato do que seria uma família ideal, a qual seria suficientemente adequada para cumprir certas funções diretamente relacionadas e, acima de tudo, determinantes do processo de escolarização de seus filhos. Além disso, tal abstração de família ideal dialoga com uma generalização igualmente abstrata e preconceituosa da organização familiar dos alunos, tida como imprópria e geradora de distúrbios e de dificuldades de aprendizagem. Nessa perspectiva, a culpabilização das famílias pelo desempenho escolar dos alunos coexiste com a proposta de que a escola precisa assumir tarefas supostamente familiares.

Souza (2010), analisando textos de políticas públicas em educação do Estado de São Paulo, constatou a presença de concepções depreciativas a respeito das classes populares, as quais vinham acompanhadas da ideia de que a escola precisa assumir o papel da família. Tal perspectiva acaba por transformar a instituição escolar em um espaço principalmente de socialização, tendo a sua capacidade de cumprir sua função social prejudicada. Concepções muito semelhantes a essas permeiam a elaboração de diversas propostas parlamentares.

Nota-se que a defesa da presença da Psicologia na Educação apóia-se aparentemente no argumento de que tais profissionais são formados para atuar auxiliando individualmente participantes do ambiente escolar cujos problemas de ordem individual, biológica e/ou familiar estejam dificultando o processo de aprendizagem, sejam esses participantes alunos ou professores, com predomínio do foco nos primeiros. Nesse sentido, é possível observar que o mote de algumas proposições é justamente a implantação de serviços de atendimento psicológico direcionados especificamente para os alunos, como pode ser ilustrado pelas passagens da PLC 13/2007 - "Acrescente-se ao art. 208, da Constituição Federal, o seguinte inciso VIII: 'Art. 208 (...) VIII - atendimento ao educando, nos ensinos fundamental e médio, por meio de equipe de avaliação formada por psicólogos e assistente sociais, em parceria com os professores" - e da PLM 417/2007 - "Art. $4^{\circ}$ III. Prestar atendimento a crianças e adolescentes com problemas emocionais, psico-motores e psico-pedagógicos".

Embora apareçam nos textos acima referências a outros participantes do contexto escolar com os quais o psicólogo poderá articular seu trabalho, o foco da intervenção continua sendo o aluno e o objetivo principal parece ser produzir mudanças no comportamento dos educandos para que esses aprendam. As origens dos problemas enfrentados pelas escolas da rede pública acabam, então, por serem depositadas em apenas um protagonista do processo de escolarização - o aluno. Entre essas proposições legislativas cujo foco é a implantação de atendimento psicológico para os alunos, merece destaque a Indicação n 2410/2008 oriunda da ALESP, que traz a proposta de oferecimento de atendimento psicopedagógico a alunos com "problemas no aprendizado", baseada na solicitação de uma aluna de uma 
escola estadual paulista. Destaca-se a seguinte passagem de autoria da estudante:

O objetivo desta lei é tornar o ambiente de aprendizagem das escolas públicas estaduais mais proveitoso, sem alunos com defasagem na aprendizagem devido a situações e problemas que trazem de suas famílias, ou ainda dificuldades no relacionamento com o ambiente coletivo.

Um primeiro aspecto presente na proposta é a solicitação de que os atendimentos sejam feitos por psicopedagogos. De acordo com Antunes (2003), o surgimento da psicopedagogia acontece quando a Psicologia Escolar e Educacional passa a conceber como insustentável atuar desconsiderando os fatores intraescolares produtores e reprodutores de dificuldades escolares e de estigmas no ambiente escolar. Em decorrência dessa autocrítica feita aos atendimentos tradicionalmente oferecidos pelos psicólogos, esses acabam por se retirar do espaço escolar e, nesse movimento, abre-se espaço para a introdução da psicopedagogia, a qual vem oferecer um trabalho que, em sua maioria, continua tendo como foco questões relacionadas ao alunado. Assim, a proposta da estudante vem ao encontro dessa psicopedagogia que desconsidera as inúmeras determinações do processo de escolarização ao conceber que é preciso prestar atendimento àqueles alunos cujos problemas oriundos de seu ambiente familiar dificultam a aprendizagem e implicam em prejuízo para os demais alunos com os quais convivem. Porém, não podemos deixar de destacar que esse pedido de ajuda é absolutamente legítimo, por se tratar de uma demanda histórica e socialmente construída por estas áreas de conhecimento, Psicologia e Psicopedagogia, tendo em vista as intervenções que tradicionalmente ofereceram para a nossa sociedade.

No entanto, ao vermos essa concepção materializada nas proposições legislativas, ao nos depararmos com a desconsideração dos mecanismos escolares que dificultam a aprendizagem e com a desresponsabilização das políticas educacionais, dos sistemas de ensino e, em suma, do sistema sociopolítico vigente, entramos em um engodo no qual uma das maiores vítimas desse processo, os alunos, passam a ser culpabilizados e incorporam tal papel (Moysés \& Collares, 1994). Todavia, há proposições legislativas que advogam por uma atuação mais ampliada do psicólogo, abrangendo também professores e funcionários, como pode ser observado no trecho abaixo extraído da PLM 280/2009:

Art $2^{\circ} \mathrm{O}$ Programa de Assistência Social e Psicológica nas instituições da rede municipal de ensino nos níveis infantil, fundamental, e médio objeto desta lei destina-se a assegurar o atendimento e acompanhamento dos alunos, seus familiares, professores e trabalhadores das instituições de ensino por psicólogos e assistentes sociais.

As propostas que preveem que o psicólogo não atue apenas com os alunos permitem o acesso a outros participantes do processo escolar, o que é fundamental e se configura como um primeiro passo para a atuação em Psicologia Escolar e Educacional a partir de uma perspectiva crítica. Tendo em vista que a queixa escolar é um produto coletivo, resultante de inúmeras relações e práticas educativas que se engendram no ambiente escolar e sendo função do psicólogo escolar intervir nesse campo de forças com o intuito de romper a produção e manutenção da queixa escolar (Machado, 2003), faz-se necessário identificar nos textos das proposições o que se espera mais claramente como contribuição da Psicologia quando são envolvidos nas ações propostas outros participantes do ambiente escolar, para além dos educandos.

A partir da leitura das propostas parlamentares, é possível notar que o psicólogo é convocado a contribuir na elaboração e desenvolvimento de práticas pedagógicas e, ao mesmo tempo, é também solicitado a orientar professores e/ou familiares sobre como lidar com os alunos. A palavra orientar sugere que o psicólogo tem um saber acima dessas pessoas e sabe de antemão a saída para a superação dos problemas que ocorrem no contexto escolar. Além disso, o foco ainda permanece nos alunos, como pode ser ilustrado pela passagem retirada da PLC 837/2003:

$\mathrm{O}$ atendimento de profissionais especializados, integrantes da equipe escolar, possibilita apoiar e orientar os alunos e suas famílias, em busca de melhores alternativas para o sucesso no processo de aprendizagem e de integração escolar e social. Da mesma forma, os professores e professoras poderão ser orientados sobre como agir, na sala de aula e em outras circunstâncias, em relação às situações que possam interferir negativamente nos processos individuais e coletivos de aprendizagem.

Além dessas propostas que consideram a participação na elaboração das práticas pedagógicas e sugerem um trabalho de orientação a respeito dos alunos, é importante destacar que algumas pontuam a importância das relações que são estabelecidas no ambiente escolar e a influência que o modo como os equipamentos de ensino estão organizados exerce no processo de escolarização, como pode ser visto abaixo na PLC 3154/2004:

O que justifica a proposta, é a compreensão de que as condições psicológicas dos sujeitos participantes do processo educativo (educadores e educandos) e o modo como estão organizadas as escolas são interferentes diretos no processo de aprendizagem. Desta forma, a presença do psicólogo na equipe de trabalho escolar, coloca-se como necessária no sentido de oferecer suporte, de um lado para os educadores em suas buscas de estratégias para efetivar as práticas pedagógicas e, de outro, para os educandos em seus propósitos de alcançar a autonomia e a inclusão social.

Essa diversidade de concepções encontradas a respeito de como a Psicologia pode contribuir no campo da Educação, em quais questões o profissional deve atuar e com quais atores do processo escolar seu trabalho precisa 
ser desenvolvido também se reflete na variedade de formas de inserção do psicólogo no contexto escolar. Há aquelas que advogam pela criação do cargo de psicólogo nas Secretarias de Educação, outras dispõem sobre a obrigatoriedade de cada equipamento de ensino contar com um profissional da área e há inclusive aquelas que afirmam que o atendimento deve ser prestado por psicólogos vinculados ao Sistema Único de Saúde e, portanto, oriundos da área da saúde.

Importante pontuar que, como afirmam Tanamachi e Meira (2003), o que caracteriza o psicólogo escolar não é seu local de trabalho, mas sim seu compromisso teórico e prático com as questões da educação. Entretanto, o fato de psicólogos que atuam na área da saúde serem designados para atender alunos com queixas escolares parece implicar em um risco ainda maior de tais questões serem abordadas a partir de uma perspectiva individualizante, tendo em vista que o psicólogo não terá contato com o cotidiano escolar em que essa queixa se produz e possivelmente possui formação em outra área da Psicologia que não a Psicologia Escolar e Educacional, podendo, por conta disso, não ter se apropriado das discussões e críticas recentemente feitas pela/na área. Faz-se necessário, portanto, considerar o quanto as concepções a respeito da atuação do psicólogo na Educação, expressas nos textos legislativos, aproximam-se dessa perspectiva crítica em Psicologia Escolar e Educacional que vem se desenvolvendo como campo de pesquisa e atuação. É importante avaliar, ainda, se o papel atribuído ao psicólogo nessas proposições se relaciona ou não com a identidade que a área vem buscando construir para si nas últimas décadas.

Por fim, nota-se que o psicólogo é visto como aquele profissional que irá auxiliar na melhoria da qualidade do ensino oferecido pela rede pública, o que em linhas gerais coincide com o compromisso político com a transformação da realidade educacional e social assumido pela Psicologia Escolar e Educacional crítica. Porém, o foco das intervenções propostas continua sendo, em maior ou menor grau, os alunos. Isto é, os problemas de escolarização ainda são predominantemente vistos como resultado de questões individuais ou da utilização de práticas pedagógicas inadequadas para determinados alunos. Desse modo, as soluções propostas para a superação dos problemas enfrentados pela rede pública de ensino permanecem focadas em alterações de um ou outro aspecto do ambiente escolar, o que a experiência tem mostrado ser insuficiente.

\section{Considerações finais}

A análise de proposições legislativas configurou-se como um caminho interessante para a compreensão de como a Psicologia vem se mostrando presente nas propostas parlamentares para o campo educacional. Buscou-se identificar quais são as concepções de Psicologia e de Educação que sustentam tais propostas e, a partir disso, o que se espera que os psicólogos realizem na educação e em benefício de quem ou do quê. Partindo dessa perspectiva, esta pesquisa teve como um dos objetivos responder à seguinte indagação: é possível afirmar que uma perspectiva crítica e comprometida de Psicologia encontra-se expressa nas políticas pensadas para o campo da Educação?

Pode-se perceber que há uma distância entre o que a área de Psicologia Escolar e Educacional vem defendendo a partir de uma Psicologia crítica e comprometida politicamente com a melhoria da educação pública e aquela que aparece nos textos parlamentares. A Psicologia que consta nas propostas analisadas é tida como um campo que irá contribuir de algum modo para a Educação e, consequentemente, para a sociedade como um todo, porém, a atuação prevista nos textos permanece predominantemente focada no indivíduo e vinculada a uma concepção instrumental de Educação. Nota-se que a defesa da presença dos psicólogos nos equipamentos de ensino apoia-se, aparentemente, no argumento de que tais profissionais são formados para atuar auxiliando individualmente participantes do ambiente escolar cujos problemas de ordem individual, biológica e/ou familiar estejam dificultando o processo de aprendizagem.

Nesse sentido, é preciso que os conhecimentos produzidos pela Psicologia Escolar e Educacional a respeito da forma como a estrutura do sistema de ensino produz e sustenta a queixa escolar sejam de fato apropriados pelos psicólogos, pelos professores e diretores da rede pública de ensino, pelos parlamentares e, em suma, pela sociedade como um todo, para que as demandas por melhorias na escola pública resultem em proposições legislativas de fato coerentes com tal propósito. De modo que essas propostas não sejam mais apoiadas em concepções preconceituosas a respeito dos alunos e comprometidas com outros interesses que não a promoção de uma educação de qualidade.

Por fim, destaca-se que a aproximação com o sistema legislativo e o contato com o conteúdo dos textos parlamentares possibilitaram conhecer o processo de elaboração de propostas políticas para o campo da educação e quais concepções orientam tais ações, evidenciando a importância de se desenvolverem pesquisas nesse campo. Além disso, essa primeira análise realizada revelou a necessidade de serem feitas pesquisas que tenham como propósito contextualizar historicamente o surgimento de cada proposição legislativa sobre a inserção do psicólogo na educação, tendo em vista quais questões e demandas sociais estão presentes no momento da elaboração das legislações. Aprofundar o conhecimento sobre o contexto histórico do surgimento das proposições legislativas, mapeando suas origens, será um caminho interessante para o desvelamento de quais interesses e propósitos estão guiando a construção de políticas para o campo da educação.

\section{Referências}

André, M. E. D. A. (1983). Texto, contexto e significado: Algumas questões na análise de dados qualitativos. Cadernos de Pesquisa, (45), 66-71.

Antunes, M. A. M. (2003). Psicologia e Educação no Brasil: um olhar 
histórico-crítico. Em M. E. M. Meira \& M. A. M Antunes (Orgs.), Psicologia escolar: teorias críticas (pp. 139-168). São Paulo: Casa do Psicólogo.

Indicação da Assembleia Legislativa do Estado de São Paulo n. 2410 de 2008. (2008). Recuperado: 06 set 2010. Disponível: http://www. al.sp.gov.br/portal/site/Internet/ListaProjetos?vgnextoid=b45fa965 ad37d110VgnVCM100000600014acRCRD\&tipo=9

Machado, A. M. (2003). O psicólogo trabalhando com a escola: intervenção a serviço do quê? Em M.E.M. Meira \& M. Antunes (Orgs.), Psicologia e Educação: práticas críticas (pp. 62-85). São Paulo: Casa do Psicólogo.

Meira, M. E. M., \& Antunes, M. A. M. (Orgs.). (2003). Psicologia escolar: teorias críticas. São Paulo: Casa do Psicólogo.

Moysés, M. A. A., \& Collares, C. A. L. (1994). A transformação do espaço pedagógico em espaço clínico (A patologização da educação). Em Alves e cols. (Orgs.), Cultura e Saúde na Escola (pp. 25-31). São Paulo: FDE.

Oliveira, R. F. (2009). Política Educacional no Brasil: qual o papel do Poder Legislativo. Curitiba: Protexto/FAPEMIG.

Patto, M. H. S. (1990). A produção do fracasso escolar. São Paulo: T. A. Queiroz.

Patto, M. H. S. (2007). "Escolas cheias, cadeias vazias" - Nota sobre as raízes ideológicas do pensamento educacional brasileiro. Estudos Avançados, 21(61), 243-266.

Patto, M. H. S. (2010). Exercícios de indignação: escritos de educação e psicologia. São Paulo: Casa do Psicólogo.

Projeto de Lei $n$. 2513, de 18 de Novembro de 2003. (2003). Projeto apresentado na Câmara dos Deputados, dispõe que em toda escola, pública e privada, seja obrigatória a presença de profissional da área de Psicologia. Recuperado: 28 ago 2010. Disponível: http://www.camara. gov.br/proposicoesWeb/fichadetramitacao?idProposicao=143216

Projeto de Lei n. 280, de 05 de Maio de 2009. (2009). Projeto apresentado na Câmara Municipal de São Paulo, dispõe sobre a instituição de programa de assistência social e psicológica nas instituições da rede municipal de ensino. Recuperado: 09 set 2010. Disponível: http://camaramunicipalsp.qaplaweb.com.br/iah/ fulltext/projeto/PL0280-2009.pdf

Projeto de Lei n. 3154, de 17 de Março de 2004. (2004). Projeto apresentado na Câmara dos Deputados, dispõe sobre a obrigatoriedade das escolas públicas e privadas contratarem Assistentes Sociais e Psicólogos. Recuperado: 28 ago 2010. Disponível: http://www.camara.gov.br/proposicoesWeb/fichadetra mitacao?idProposicao=156409

Projeto de Lei n. 417, de 13 de Junho de 2007. (2007). Projeto apresentado na Câmara Municipal de São Paulo, fixa em todas as unidades de ensino do município de São Paulo a lotação de psicólogo e dá outras providências. Recuperado: 09 set 2010. Disponivel: http://camaramunicipalsp.qaplaweb.com.br/iah/ fulltext/projeto/PL0417-2007.pdf

Projeto de Lei n. 441, de 16 de Maio de 2007. (2007). Projeto apresentado na Assembleia Legislativa do Estado de São Paulo. Assegura atendimento por psicólogos e assistentes sociais aos alunos das escolas públicas de educação básica. Recuperado: 06 set 2010. Disponível: http://www.al.sp.gov.br/portal/site/Internet/Li staProjetos?vgnextoid=b45fa965ad37d110VgnVCM10000060001 4acRCRD\&tipo $=1$

Projeto de Lei n. 7500, de 10 de Outubro de 2006. (2006). Projeto apresentado na Câmara dos Deputados, para determinar a obrigatoriedade da assistência psicológica a educadores e educandos da educação básica. Recuperado: 28 ago 2010. Disponível: http://www.camara.gov.br/proposicoesWeb/fichadetra mitacao?idProposicao $=334450$

Projeto de Lei n.1040, de 08 de Outubro de 2003. (2003). Projeto apresentado na Assembleia Legislativa do Estado de São Paulo que institui o Serviço Psicológico Escolar nas escolas estaduais de $1 .^{\circ}$ e $2 .^{\circ}$ graus. Recuperado: 06 set 2010. Disponível: http://www. al.sp.gov.br/portal/site/Internet/ListaProjetos?vgnextoid=b45fa965 ad37d110VgnVCM100000600014acRCRD\&tipo=1

Projeto de Lei n.13, de 05 de Fevereiro de 2007. (2007). Projeto apresentado na Câmara dos Deputados, garante aos alunos de ensino fundamental e médio atendimento por equipe de avaliação formada por Psicólogos e Assistentes Sociais. Altera a Constituição Federal de 1988. Recuperado: 28 ago 2010. Disponível: http:// www.camara.gov.br/proposicoesWeb/fichadetramitacao?idPropos icao $=339971$

Projeto de Lei n.837, de 24 de Abril de 2003. (2003). Projeto apresentado na Câmara dos Deputados, dispõe sobre a participação de assistentes sociais e psicólogos na estrutura funcional das escolas. Recuperado: 28 ago 2010. Disponível: http://www.camara.gov.br/proposicoesWeb/fichadetramitacao?idP roposicao $=112943$

Saviani, D. (2001). Escola e Democracia: teorias da educação, curvatura da vara, onze teses sobre a educação política. Campinas, SP: Autores Associados.

Souza, M. P. R. (2009). Psicologia Escolar e Educacional em busca de novas perspectivas. Revista Semestral da Associação Brasileira de Psicologia Escolar e Educacional (ABRAPEE), 13(1), 179-182.

Souza, M.P.R. (2010). Psicologia Escolar e políticas públicas em Educação: desafios contemporâneos. Em Aberto, 23(83), 129149.

Souza, M. P. R., \& Cunha, B. B. B. (2010). Projetos de Lei e políticas públicas: o que a psicologia tem a propor para a educação? Em Conselho Regional de Psicologia de São Paulo e Grupo 
Interinstitucional Queixa Escolar (Orgs.), Medicalização de crianças e de adolescentes: conflitos silenciados pela redução de questões sociais à doença de indivíduos (pp. 215-228). São Paulo: Casa do Psicólogo.
Tanamachi, E. R. (2002). Mediações teórico-práticas de uma visão crítica em Psicologia Escolar. Em M. P. R. Souza, E. R. Tanamachi \& M. Rocha (Orgs.), Psicologia e Educação: Desafios teóricopráticos (pp. 73-103). São Paulo: Casa do Psicólogo.

Tanamachi, E. R., \& Meira, M. E. M. (2003). A atuação do psicólogo como expressão do pensamento crítico em psicologia e educação. Em E. R. Tanamachi \& M. E. M. Meira (Orgs.), Psicologia Escolar: práticas críticas (pp. 11-62). São Paulo: Casa do Psicólogo.

Recebido em: 16/08/11

Reformulado em: 17/01/12

Aprovado em: 27/02/12

\section{Sobre as autoras}

Mariana Guimarães Pasqualini (marianagp02@gmail.com)

Graduada em Psicologia pelo Instituto de Psicologia da Universidade de São Paulo (2010).

Endereço: Rua Sóror Angélica, 555 apto 44L Santana - São Paulo - SP CEP: 02452-060

Marilene Proença Rebello de Souza (marileneproenca@hotmail.com)

Professora Livre Docente da Universidade de São Paulo, Instituto de Psicologia, Coordenadora do Programa de Pós-Graduação em Psicologia Escolar e do Desenvolvimento Humano e do Laboratório Interinstitucional de Estudos e Pesquisas em Psicologia Escolar da Universidade de São Paulo. Pesquisadora do Conselho Nacional de Pesquisa e Membro da diretoria da ABRAPEE (Associação Brasileira de Psicologia Escolar e Educacional).

Endereço: Av. Prof. Mello Moraes, 1721. Bloco A. Sala 155, Cidade Universitária. São Paulo - SP CEP: 05508-030

Cárita Portilho de Lima (carita.portilho@yahoo.com.br)

Mestranda pelo programa de Pós-Graduação em Psicologia Escolar e do Desenvolvimento Humano do Instituto de Psicologia da Universidade de São Paulo. Psicóloga Escolar do Município de Taboão da Serra.

Endereço: Rua Monte Caseros, 126, apto 2A - Vila Gomes - São Paulo - SP CEP: 05590-130

Esta pesquisa foi desenvolvida com apoio financeiro do Programa de Iniciação Científica Santander/USP. 